\title{
La democracia en México, entre la participación política y la gobernabilidad
}

\author{
Democracy in México, Between Political \\ Participation and Governance
}

\section{Genoveva Flores Quintero}

Recepción: 28 de Agosto de 2015

Aceptación: 4 de septiembre de 2015

\section{Resumen}

El artículo describe la evolución de la sociedad mexicana y su relación con el Estado y los diferentes gobiernos en el poder, a partir de Hernán Cortez y Moctezuma hasta el gobierno actual de Enrique Peña Nieto. Tiene por objeto describir la evolución de la sociedad civil mexicana tomando como referente a los diferentes presidentes de México y sus posturas, leyes y decisiones frente a la participación ciudadana. Evidencia el surgimiento y el triunfo de candidatos independientes en las elecciones 2015 como una muestra de la evolución de la sociedad mexicana y de la forma de hacer política.

Palabras clave: sociedad, Estado, democracia, partidos, participación política.

\section{Abstract}

The article describes the evolution of Mexican society and its relationship with the state and the various governments in power from Hernan Cortez and Montezuma to the current government of Enrique Peña Nieto. It is to describe the evolution of Mexican civil society taking as reference the different presidents of Mexico and their positions, laws and decisions against public participation. Evidenced by the emergence and success of independent candidates in the 2015 elections as a sign of the evolution of Mexican society and the way of doing politics.

Keywords: society, State, democracy, parties, political participation. 


\section{Introducción}

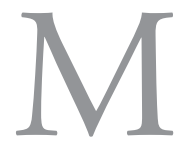
éxico se diferencia del resto de América Latina por la estabilidad y gobernabilidad que mantuvo por más de 70 años en el siglo XX; pero esta paz estuvo sustentada en el corporativismo y en la debilidad de la sociedad civil, como lo afirma la politóloga Soledad Loaeza cuando señala que durante este lapso el sistema político mexicano estuvo basado en la "no participación política". Esto puede advertirse aún en las fotografías del periodo que va de la década de los 30 y hasta casi el final de los años 80. En ellas podemos ver la Plaza de Armas (el Zócalo) llena de burócratas, sindicalistas, sectores populares enarbolando banderas, mantas y carteles de apoyo a los presidentes de la "era del PRI", como le llama el mexicanista Peter Smith; pero es necesario analizar a profundidad las bases teóricas de la ciudadanía y la política para advertir que estas manifestaciones convocadas desde las cúpulas políticas, tenían poco de acciones voluntarias, conscientes y más bien era el resultado de un entramado de relaciones determinadas por el corporativismo, la verticalidad de mando y la toma decisiones de una pequeńa élite.

Sin embargo, en el último cuarto del siglo XX esa tendencia comenzó a cambiar gracias al empuje de la sociedad civil y del descontento de las clases medias urbanas y rurales, generado por un ciclo de sucesivas crisis económicas. Así fue como inició el agrietamiento del aparentemente monolítico poder del Partido Revolucionario Institucional (PRI), y comenzó a fraguarse una verdadera oposición tanto de derecha como de centro-izquierda, que permitió generar una positiva incertidumbre en los resultados de las elecciones, una auténtica lucha por el poder, la diversificación de los gobiernos locales y estatales, y finalmente una alternancia en la presidencia de la República.

Importantes cambios generacionales y la poca habilidad de las cúpulas partidistas en la primera década del siglo XXI, rompieron la estrecha relación que tenía la sociedad con los partidos políticos de oposición y profundizaron la histórica separación con el Estado. Amplios sectores comenzaron a distanciarse de los partidos de izquierda y derecha. Este 
debilitamiento del Partido de la Revolución Democrática, PRD (centro-izquierda), y Partido Acción Nacional, PAN (derecha), así como el aprendizaje del PRI de 12 años de oposición fuera de la presidencia, comenzaron a perfilar el regreso del mismo a la presidencia. Una de las claves fue el haber mantenido un núcleo de gobernadores de los Estados (departamentos) alineados a sus prácticas políticas y corporativas, que fueron un contrapeso por tener la capacidad de manejar presupuestos estatales, mientras que la Cámara de Diputados permanecía dividida entre las principales fuerzas políticas, limitando la actuación del Ejecutivo federal durante la transición.

El regreso del PRI a la presidencia en el 2012 no se sustentó en una democratización, ni contó con el fortalecimiento de la sociedad civil o con la mejora en la participación política, de hecho puede señalarse que hubo un retorno a las tácticas corporativas de antaño, con la consecuente pérdida de credibilidad, esta vez del sistema político en su conjunto, incluyendo a los partidos de oposición, y lo que resultó más grave, en la pérdida de credibilidad respecto a la construcción de la democracia y a la autoridad electoral, que tanto trabajo había costado construir.

En este panorama las nuevas posibilidades de internet y de las redes sociales, como un espacio de comunicación sin mediaciones, de amplio consumo y fuera del control de los aparatos corporativos, parecen dar un aire a la democracia mexicana que, ya en las elecciones intermedias del verano de 2015, posibilitó la llegada de candidatos independientes: un gobernador y un diputado, apoyados por amplios sectores sociales; pero aún falta su prueba de fuego, continuar en su gestión con este nexo con la sociedad que les permitió ganar elecciones.

\section{Estado débil y hombres fuertes}

La decisión de Hernán Cortés de desoír a sus capitanes quienes les sugerían instalar su palacio en la ribera de la laguna, y no en el centro, donde estaba el palacio de Moctezuma, el corazón del imperio que aca- 
baba de conquistar, y donde finalmente quedó instalado, no sólo el palacio virreinal, sino también la catedral, pinta de cuerpo entero el genio político del conquistador español, quien de este modo se adueñó del centro simbólico del poder del que fuera el imperio de Moctezuma. Este acto fundacional nos habla de la concepción del poder en ambas épocas: la prehispánica con un monarca en el centro y la virreinal con una autoridad también central que gobernaba y tenía el poder militar. Y en lo simbólico la derrota absoluta, al sustituir un palacio por otro, y el Templo Mayor por la Catedral Metropolitana.

La característica del poder centrado en una sola persona se reforzó durante los tres siglos coloniales con la llegada de los virreyes, a pesar de la figura de la Audiencia, que en el papel actuaba como contrapeso del Ejecutivo, y de mecanismos de control de gestión como lo eran los juicios de residencia, pues nunca llegaron a aplicarse a los virreyes. Además debe comprenderse que las comunicaciones de entonces eran lentas e imposibilitaban una coordinación directa del virrey con el rey español, así que todo era regido por la lealtad entre ambos.

Estos patrones: la figura del Tlatoani mexica (monarca) a quien no se podía tocar o ver directamente a los ojos, y la concentración del poder en una autoridad central, se fueron arraigando en la sociedad novohispana, aunque había importantes contrapesos del poder virreinal como lo eran la autoridad religiosa y los comerciantes de la Ciudad de México, el Virrey era la figura central de cuya voluntad dependía la vida de la nación. De tal forma que no es extraño que en el revuelto siglo XIX, se volviera a presentar como atractiva la figura del caudillo.

En esta breve visión retrospectiva sería burdo decir que el siglo XIX mexicano fue pobre en la discusión política. De hecho desde las conspiraciones de 1808 y en los periódicos decimonónicos se puede seguir el debate sobre el proyecto de nación entre liberales y conservadores con instituciones en muchos órdenes, y podemos enumerar una larga lista de intelectuales de ambas tendencias que mantuvieron interesantes polémicas sobre política, ciudadanía y espacio público; sin embargo, en 
la renovación de las élites políticas del México independiente, la fuerza angular fueron las caudillos militares.

Esta élite de las armas se gestó en los once años que duró la Guerra de Independencia, cuando aparecen figuras emblemáticas como José María Morelos, independentista que en su origen fue sacerdote; Agustín de Iturbide, quien era militar realista, o Vicente Guerrero, quien después de resistir en la última etapa de la guerra pacta la paz; pero también figuras como Antonio López de Santa Anna sin cuya trayectoria en el poder no puede comprenderse el siglo XIX mexicano.

La guerra de independencia de Texas (1835-36), la intervención norteamericana (1846-1848) y la invasión francesa (1862-1867), reforzaron la importancia de los caudillos militares en la esfera del poder y en el imaginario de la población mexicana, de tal forma que los golpes militares (pronunciamientos) eran el mecanismo recurrente de renovación de poder en el siglo XIX, aunque se realizaron elecciones con el voto limitado ${ }^{1}$.

Después de este siglo violento, el triunfo definitivo de los liberales a partir de la restauración de la República en 1867, no cambió el concepto elitista de los electores, pero si permitió la llegada de caudillos con un sólido programa político como lo fueron el presidente Benito Juárez y posteriormente Porfirio Díaz; pero la golpeada economía, el endeudamiento externo y la disolución del orden legal, económico, cultural y social propiciado por los 60 ańos de confrontaciones, habían dejado a la sociedad empobrecida y alejada de la esfera del poder y concentrada en la sobrevivencia. Así que teníamos una sociedad débil alejada del espacio público, y un Estado débil también, debido a los constantes cambios en el gobierno y la lucha de facciones, que no permitieron la consolidación de instituciones políticas. De hecho la evolución de la Universidad Pontificia, del Colegio de San Carlos, del comercio de la Ciudad de México y otras instituciones de orden cultural o económico, resultan un tanto excepcionales en los convulsos tiempos del siglo XIX.

1 El voto era restringido a las mayorías dado que dependía de la condición económica y del género

(Velázquez, 2008). 
El periodo conocido como el porfiritato (1876-1910), cuando el gobierno fue llevado por el caudillo militar liberal, Porfirio Díaz, quien centró en su persona el poder del Estado, a través de una combinación entre el control político de jefes militares, caudillos políticos regionales, y la conformación de nuevas elites económicas mexicanas y extranjeras centradas en una explotación capitalista de recursos como la plata, el tabaco, el henequén, el petróleo y poseedoras de servicios como los ferrocarriles, la electricidad y los bancos, concesiones que se otorgaron según la voluntad del presidente.

Como se sabe el periodo concluye con una serie de revoluciones sociales de distintos signos, que genéricamente nombramos como la Revolución Mexicana, las cuales confluyeron en un punto: el derrocamiento de Porfirio Díaz. Para no profundizar demasiado este marco histórico es importante decir que esta nueva confrontación armada reforzó la figura del caudillo militar; pero introdujo a la esfera política una importante variación: la toma del poder de un grupo cohesionado de caudillos militares que se pasaron el poder entre ellos, crearon instituciones políticas, y que poco a poco fueron separando las esferas del gobierno federal de las elites militares, conformando de esta manera uno de los principales pilares de la gobernabilidad del siglo XX, cuando los militares aceptaron quedar fuera del partido hegemónico y de la sucesión presidencial. Un rasgo distintivo de la historia política de México dentro del siglo XX latinoamericano.

\section{La sociedad y el Estado mexicano postrevolucionario}

Hasta ahora hemos explorado la evolución del vértice superior de la pirámide política mexicana; pero para poder comprender la estabilidad política del sistema político en casi un siglo, es necesario responder la pregunta ¿qué pasó en la relación del Estado mexicano y la sociedad después de la Revolución Mexicana? 
El asesinato del presidente electo Álvaro Obregón (1928) por un fanático católico (cristero), marca el inicio de un periodo de la historia política conocido como el Maximato, que fue el gobierno "tras el trono" de un ex presidente, Plutarco Elías Calles, sobre tres presidentes sucesivos hasta 1934, cuando fue electo presidente el general Lázaro Cárdenas del Río. Este año es un punto de inflexión para responder la pregunta formulada, ya que el Cardenismo se centró en la política de masas, como un elemento fundamental para activar la participación de amplios sectores sociales (agrario, obrero y sectores urbanos populares). De hecho fue un mecanismo organizativo de grupos, en su origen como grupos de presión, para mantener las reformas derivadas de la Revolución Mexicana (Córdova, 1974).

A pesar de que su génesis fue propiciada por el presidente, tuvo la fuerza impulsora de los grupos de presión, pero con el tiempo y la llegada de políticos más moderados y menos populistas, se convirtió en un recurso eficaz de los presidentes para el control de las masas. Generó además el establecimiento de un sistema clientelar que sirvió al presidente en turno para colocarse en el vértice de la pirámide política, controlando al mismo tiempo el poder que tenía como jefe del Ejecutivo federal, y como líder indiscutible de su partido, el PRI, imponiendo con ello su ritmo y voluntad política en la esfera pública, sin discusiones.

De hecho una de las premisas de la estabilidad política que siguió a los años 30 fue el control del Estado sobre la participación política, a través de las centrales como la Confederación de Trabajadores de México, la Confederación Nacional Campesina, y la Confederación Nacional de Organizaciones Populares, las tres grandes centrales de masas del Partido de la Revolución Mexicana, antecesor del PRI. Esta estabilidad tuvo un valor importante para una creciente clase media, la cual atendía los discursos explícitos e implícitos de los políticos que le atribuían a la participación ser una fuente de conflictos, divisiones e inestabilidad (Loaeza, 2008). 
Vale la pena hacer un señalamiento importante, observado por James M. Malloy no sólo en México, sino en toda América Latina y es el nacimiento de una clase media muy ligada a las estructuras del Estado, lo que él llama "burocratización prematura", esto es la tendencia del aparato gubernamental formal a expandirse con más rapidez que las estructuras socioeconómicas básicas (Malloy en Camp, 1997). Así que es una clase media cuyo bienestar, recientemente adquirido, depende de un Estado hegemónico, y por lo tanto sumisa. Con dos posiciones frente al espacio público, obediente e integrada a la amorfa Confederación Nacional de Organizaciones Populares o bien apolítica y callada.

El discurso político del periodo de la II Guerra Mundial y de la postguerra hacían énfasis en el concepto de la "unidad nacional" primero frente a los posibles enemigos externos, como resultado de la polarización de las naciones en la que participó México, de manera marginal en lo militar, pero no tanto en lo referente a su posición geoestratégica al sur de Estados Unidos.

Después, en la Guerra Fría, y dentro del alineamiento anticomunista, la política de "unidad nacional" se centró en los enemigos internos. El Desarrollo Estabilizador en México (1952-1970) es también el periodo de mayor hegemonía del Estado y su partido el PRI, y de confrontación armada con los grupos más radicales de izquierda, los cuales se encontraban, por una parte limitados en su participación política por su exclusión del partido oficial y por la otra impedidos de formar un partido propio por el endurecimiento de la legislación electoral que le cerraba la puerta en las elecciones. En esta época se fortalece la idea de que la participación política, las organizaciones independientes y la protesta política, son elementos de desestabilización. Esto genera leyes contrarias a la inclusión de los ciudadanos en el espacio público. El ejemplo recurrente de este endurecimiento de las leyes en contra de la participación es la creación del delito de "disolución social" de muy amplio espectro, que criminalizó las protestas políticas (Castellanos, 2007). 
Pero México, como otros países de la región y del mundo, había experimentado "las revoluciones silenciosas" del siglo XX, de las que habla el historiador Eric Hobsbawm (1998) y su sociedad había cambiado radicalmente al pasar de una sociedad fundamentalmente rural, a una en la que sus ciudades crecían aceleradamente, y dentro de ellas la población urbana era cada vez más significativa en la proporción poblacional nacional. Como resultado de esta migración la cosmovisión sobre el espacio público cambió; las mujeres tomaron un papel más activo en la vida pública, y los jóvenes de clases medias se convirtieron en actores políticos, que no podían ser controlados desde ninguna de las grandes centrales de masas creadas en la postrevolución y quedaban fuera de las relaciones clientelares que generaban.

Los politólogos coinciden en que la matanza de estudiantes de 1968 en la plaza de las Tres Culturas, en la moderna unidad habitacional Tlatelolco, es la ruptura más importante del Estado y su partido con la sociedad, y en particular con las clases medias (Meyer, 2005; Loaeza, 2008).

\section{Génesis de la sociedad civil mexicana}

La historia de la sociedad finisecular puede bien comenzar en 1946 cuando con la promesa de modernización, y acompañando al sexenio del presidente Miguel Alemán se estrenaba una nueva estructura política, el Partido Revolucionario Institucional, del cual, hemos mencionado antes, quedaron excluidas las corrientes más combativas de izquierda, y también un modelo de industrialización basado en el sacrificio del campo en favor de la industrialización, en cuyo núcleo estuvieron el Valle de México, y las ciudades de Monterrey y Guadalajara. Asimismo, aunque el sexenio se encuentra dentro del modelo de sustitución de importaciones, es relevante mencionar que se suavizó el proteccionismo de la doctrina del "nacionalismo revolucionario" que había emanado de la Revolución Mexicana y que se introdujeron importantes reformas 
que permitieron la entrada de capital extranjero a la economía mexicana, que fue fundamentalmente norteamericano. En el campo se privilegió el crecimiento de empresarios privados, mediante la instauración del amparo agrario, que evitaba la repartición de latifundios familiares que habían sobrevivido a los dos sexenios anteriores, de los cuales el de Lázaro Cárdenas tuvo la política social más amplia (Torres, 1984).

El llamado Desarrollo Estabilizador ofreció a la sociedad mexicana, mucha de ella recientemente asentada en las ciudades grandes y medias, un periodo de estabilidad económica y de crecimiento sostenido de una planta industrial de empresas nacionales. Asimismo como motor de este desarrollo las dos principales universidades del centro del país, la Universidad Nacional Autónoma de México y el Instituto Politécnico Nacional, comenzaron un sostenido proceso de masificación al aumentar la matrícula al tamaño de la demanda de los hijos de los migrantes. $\mathrm{Y}$ un proceso similar vivieron las universidades estatales en cada una de las entidades. Así que para las familias mexicanas de aquel entonces estudiar una carrera universitaria parecía una garantía para la movilidad social y la mejora en su nivel de vida.

Los años 70 en México han sido estudiados como una década fundamental en el desarrollo de una sociedad civil no ligado al Estado mexicano. Este crecimiento organizativo al margen de las grandes corporaciones estudiadas antes fue el resultado de varios fenómenos convergentes que vale la pena explorar.

Una de las paradojas difíciles de entender del sistema político mexicano es la dualidad del discurso político: mientras en la política exterior pudo llegar a defender la Revolución Cubana, al régimen de Salvador Allende en Chile, al de los sandinistas en Nicaragua, en su política interior podía llegar a perseguir a sangre y fuego a los opositores más radicales de izquierda como sindicalistas o grupos guerrilleros. El presidente populista Luis Echeverría (1970-1976), puso en marcha una severa política interior que se conoce como la "guerra sucia", y que dio como resultado miles de desaparecidos y presos políticos. Movimientos contemporáneos internacionales en pro de los derechos humanos 
y estas condiciones internas dieron nacimiento a un movimiento de familiares que buscaban en cuarteles, cárceles y en archivos las pistas de los desaparecidos, y que con los años se convirtieron en grupos de presión del gobierno.

En esta misma década por razones estructurales se conformó un movimiento amplio de mujeres que centró sus demandas en la modificación a las vergonzosas leyes y las prácticas de la justicia en los casos de violencia sexual, así como en las demandas de espacios de atención a los problemas de género. A pesar del catalizador que representó el Año Internacional de la Mujer (1975) y de la conferencia internacional que tuvo como sede la capital mexicana. Las demandas de una legislación contra la violencia hacia las mujeres tuvieron que esperar al sexenio de Ernesto Zedillo (1994-2000) para convertirse en una realidad, pero esta persistencia de la cultura patriarcal en la esfera política, no alcanzó a atenuar el movimiento que se fortaleció en la década de los 80 y 90.

Un tercer movimiento de amplias dimensiones fue el urbano popular que también fue resultado de los profundos cambios sociales generados por la migración campo-ciudad, y que se presentó como un problema metropolitano. Los solicitantes de vivienda popular se organizaron e invadieron tierras no sólo en el sur capitalino (bosque del Ajusco) sino también en los municipios conurbados con la Ciudad de México. El gobierno federal ${ }^{2}$ había dejado de construir unidades habitacionales populares y las reservas territoriales se agotaron, así que comenzó a expulsar población hacia el vecino Estado de México; empero en términos organizativos, estos grupos demandantes de vivienda realizaban acciones en conjunto y aprendían estrategias de apropiación de terrenos en áreas de propiedad federal ${ }^{3}$.

Las organizaciones del Valle de México (Ciudad de México y municipios conurbados) nucleados en la Coordinadora Nacional del Movimiento Urbano Popular (Conamup) serían de radical importancia para

2 Entonces el Distrito Federal, dependía completamente del poder Ejecutivo y en su territorio no había la posibilidad de elegir autoridades locales.

3 Otras entidades donde también había movimientos inquilinarios o de demandantes de vivienda fueron Durango, Nayarit, Veracruz, y Sinaloa. 
el año 1985, cuando dos devastadores sismos pusieron en jaque a la Ciudad de México. Esta organización previa e independiente de los partidos políticos propiciaría el movimiento de la sociedad civil más exitoso del fin de siglo mexicano, la Coordinadora Única de Damnificados, que se mantuvo a la distancia de los mecanismos de cooptación del PRI, y de los otros partidos, y haber logrado el cumplimiento de su demanda de vivienda digna (Esteve, 1992).

Hay dos corrientes que no son de la dimensión de las que he mencionado hasta ahora y es una que se incubó dentro del seno de la Iglesia católica y que fue el directo resultado de los acuerdos del Concilio Vaticano II de 1965 y que se incubó en una organización de católicos de base, que tuvo como epicentro la Diócesis de Cuernavaca, con el obispo Sergio Méndez Arceo, ligado a la Teología de la Liberación, y que propició la organización y el trabajo de los católicos en ese Estado al sur de la capital mexicana.

Y el movimiento ecologista, en cuyo origen está PRONATURA, fundado en 1972, un grupo conservacionista enfocado a la conservación de las aves, sus promotores fueron empresarios de Nuevo León, y más tarde el anuncio de la construcción de la nucleoeléctrica de Laguna Verde, va a movilizar a grupos ecologistas opositores en los ańos 80 .

Por el lado del empresariado, ese deslinde había venido como consecuencia del discurso populista del mencionado Luis Echeverría Álvarez, con la fundación del Consejo Coordinador Empresarial, un organismo que se distanciaba del Estado y de las Confederaciones patronales tradicionales. Como se ha mencionado antes fue una reacción dentro de la paradoja, una protesta velada contra el discurso populista, el acercamiento de Echeverría al régimen de Salvador Allende, y catalizado por un fallido reparto agrario de un distrito de riego en el norte del país, y el asesinato de un importante líder empresarial, Eugenio Garza Sada, a manos de uno de los grupos guerrilleros que combatía fuertemente el Estado mexicano (Flores y Rodríguez, 2011). 


\section{Un contexto económico necesario}

Nos hemos referido a tres de las revoluciones silenciosas del siglo XX: la conversión de la población de rural a urbana; la consolidación de los jóvenes como actores políticos y el empoderamiento de las mujeres; pero aún nos falta abordar la desaparición de la clase obrera combativa, y es necesario comprender que en el centro de la ruptura entre el Estado Mexicano y la sociedad del último tercio del siglo XX, estuvieron sin duda las sucesivas crisis económicas que tuvo México entre los años 1976 y 2009, que no sólo desaceleraron el ritmo del crecimiento económico, sino que provocaron un desempleo generalizado de las clases medias; la pérdida de valor de los salarios reales y la sumisión de los sindicatos; la reducción de las clases medias urbanas; un cambio de modelo económico y como consecuencia de éste el deterioro de empresariado nacional.

La estabilidad económica del Desarrollo Estabilizador propició que se tuviera crecimiento económico de hasta el $7 \%$ anual y esto fundamentó una idea de que las cosas iban muy bien en las ciudades; una historia diferente siempre ha sido el campo mexicano que no ha registrado un boom importante en el siglo XX, y que se encuentra enfocado a la agricultura de sobrevivencia de millones de empobrecidos indígenas y mestizos, concentrados en el sur pobre de México. Pero la estabilidad no fue larga.

En 1976, durante el sexenio de Luis Echeverría, el modelo de sustitución de importaciones se agotó y México, con cierto grado de asombro, comenzó a experimentar procesos de inflación nunca antes vistos, propiciados por un manejo irresponsable de la política monetaria; asimismo la disparidad de la balanza de pagos y la falta de efectividad en la política de fomento agrario, y el mencionado enfrentamiento ideológico con el empresariado, hicieron que la paridad cambiaria con el dólar, 12.50, característica del último tramo del Desarrollo Estabilizador, fuera imposible de sostener. Aunque los reales problemas económicos estaban por verse, el hecho de que fuera la primera crisis económica 
tuvo un severo impacto en el imaginario de una sociedad que había salido herida de la crisis política de 1968; así que la presidencia de José López Portillo comenzó con serios problemas económicos y políticos.

El golpe de timón con el que inició el sexenio le permitió a López Portillo recuperar la confianza del empresariado, de los acreedores extranjeros y de los sectores populares, de hecho se puede afirmar que la oratoria del priista fue una de sus mejores armas; pero no la única, en contraste con su antecesor, y siguiendo las líneas marcadas por su Secretario de Gobernación, Jesús Reyes Heroles, abrió los espacios de participación política para la izquierda mexicana con su reforma política y complementó esta medida con una amnistía para los presos políticos que habían sobrevivido a la guerra sucia. Los sectores urbanos universitarios, especialmente de la capital mexicana recibieron bien el cambio de rumbo y se aprestaron a participar de la lucha partidaria. A partir de ese momento se inició el camino hacia la transición democrática y el paulatino debilitamiento del modelo autoritario (Loaeza, 2008).

En el ámbito económico el presidente tenía un as bajo la manga, un informe técnico que certificaba un enorme campo petrolero, Cantarell, que se encontraba en aguas someras del Golfo de México y otros en tierra, en el Estado de Tabasco. Estas reservas probadas de petróleo fueron la garantía para un préstamo internacional de grandes proporciones, que permitió atenuar la crisis y refinanciar los pagos de la deuda externa.

Fue de hecho una época de oro en lo económico, impulsada por los altos precios internacionales del petróleo, generados por la OPEP, a la que México no pertenecía, pero que acabó beneficiando a todos los países petroleros del mundo. No sólo se pudo disponer de presupuestos generosos para la construcción de escuelas, los excesos de la clase política y la compra de tecnología petrolera, sino que se tuvieron excedentes petroleros. Totalmente fuera de realidad el presidente prometió que los dos primeros años de su sexenio controlaría la crisis, cosa que hizo por el citado préstamo, los siguientes dos años adecuaría la administración pública para hacerla más eficiente y los últimos del sexenio serían para 
“administrar la abundancia”; pero eso no pasó, los programas de austeridad en Estados Unidos, y la exportación masiva de crudo por parte de México y otros países, cortaron la trayectoria ascendente de los precios petroleros. El derrumbe de la economía petrolizada de México fue un golpe que se tradujo en inflación, escasez y por supuesto devaluación. La última carta que jugó el presidente de entonces, fue de inspiración totalmente populista y política: ante la debacle los empresarios comenzaron a sacar sus capitales del país, así que el gobierno nacionalizó la banca y estableció el control de cambios, para retener la sangría económica, lo que por supuesto dio al traste con la relación entre el empresariado y el gobierno mexicano. Así que México salió del Desarrollo estabilizador con dos crisis la de 1976 y la de 1982.

De nuevo se necesitaba un préstamo para salir de la crisis, y la condición de los organismos internacionales fue que México se alineara a la tendencia internacional predominante de entonces: cambiar el modelo hacia el neoliberalismo, que tenía en su centro la liberalización de los mercados y la reducción de los gastos del Estado, especialmente los que habían sido el colchón de millones de mexicanos en la pobreza, y además el más poderoso sostén del corporativismo de obreros y campesinos, y las relaciones clientelares que permitían la estabilidad política.

Los mecanismos para salir de la crisis descansaron en las clases asalariadas y las clases medias, y estrenaron, para los mexicanos, los planes de ajuste económicos dictados desde los acreedores, que se tradujeron en una severa austeridad económica que pulverizó el valor adquisitivo del peso mexicano y el poder adquisitivo de amplios sectores poblacionales. A mediados del sexenio un evento que no se podía prever agudizó los efectos de estos planes de autoridad. Los terremotos de septiembre de 1985 en la capital mexicana, hicieron necesario un nuevo endeudamiento para la reconstrucción de edificios públicos, escuelas, y de vivienda popular, esto último presionado por el movimiento de damnificados al que nos hemos referidos antes.

Los problemas del país no se habían acabado y la semilla de la siguiente crisis había sido sembrada por Miguel de la Madrid, el primer 
presidente neoliberal, para disminuir la confrontación con los empresarios. De las primeras medidas del sexenio fue regresar el $34 \%$ de las acciones de la banca a la iniciativa privada; quienes la adquirieron no fueron los ex banqueros sino jóvenes empresarios, quienes fundaron casas de bolsas y a través de su gestión impulsaron a miles de ahorradores primerizos a invertir en el fluctuante mercado de valores. En ese entonces el mercado no estaba regulado, así que se generó una burbuja especulativa que desprendió el precio de las acciones de las condiciones reales de las empresas. De esta forma los estados contables eran lamentables, pero el precio de las acciones era sumamente alto. La burbuja especulativa reventó en sincronía con una caída en el índice Dow Jones el lunes negro del 19 de octubre de 1987. Como se puede apreciar esto llevó a la economía mexicana a niveles negativos de crecimiento; pero el peor efecto sin duda fue la inflación de tres dígitos. La receta neoliberal de inicio del sexenio se repitió para el año de 1988 con el Pacto de Solidaridad Económica, en el que se reunieron los empresarios, los dirigentes de la CTM, los directores de las empresas paraestatales como Comisión Federal de Electricidad, Petróleos Mexicanos, y el gabinete económico, para "congelar" la inflación; pero de nuevo el peso del ajuste lo sostuvieron los asalariados y fue necesario otro préstamo internacional.

Para cerrar esta breve relatoría de las crisis económicas, me referiré a la que se desata a finales de 1994, conocida como el "error de diciembre”, y a los efectos de la crisis de 2008 sobre la economía nacional.

Durante el sexenio de Carlos Salinas de Gortari, el discurso político aseguraba que gracias al neoliberalismo y en especial a la firma del Tratado de Libre Comercio con Estados Unidos, México entraría al exclusivo club de los países del primer mundo. Dejando atrás todos los lastres que habían retenido en el subdesarrollo a la economía mexicana; sin embargo, 1994 quedó registrado como uno de los años más complejos en todos los órdenes, como explicaremos abajo. En lo que se refiere a la economía el inicio de la crisis se retrasó unos meses respecto al comportamiento histórico de las mismas, que iniciaban en el último 
año del sexenio saliente y no fue el presidente Salinas de Gortari quien anunció el nuevo tropiezo, sino el presidente entrante Ernesto Zedillo. Se recuerda a esta crisis como el "error de diciembre". Su nombre, sin embargo, no describe lo que ocurrió: no se trató de un manejo errado de la economía, el origen de la crisis era estructural y no solamente de algunas medidas políticas y económicas erradas.

La crisis afectó a clases medias, empresarios, pequeños productores del campo y a los banqueros y casas comerciales, quienes habían otorgado créditos en exceso y sin control. En 1990 se reprivatizó lo que quedaba de la banca nacional, así que la crisis de los créditos y la falta de liquidez del sistema bancario era un problema de la iniciativa privada; pero en una de las más polémicas medidas para salir de la crisis, el gobierno federal convirtió la deuda privada en pública.

En el nuevo siglo, y con gobiernos de oposición en el poder, se sufrió un nuevo descalabro económico, la crisis de 2008, aunque sus efectos llegaron atenuados debido a que el sistema financiero mexicano había sido blindado contra especulación. Así que sólo se sintieron los efectos económicos de la debilidad de nuestro principal socio comercial, Estados Unidos. Aun así la caída en los precios del petróleo y la desaceleración del consumo de automóviles en Estados Unidos, así como la baja en el consumo de los estadounidenses impactaron en el presupuesto nacional dependiente del petróleo; a centros armadores de automóviles en los estados de Puebla, Estado de México, Aguascalientes, Sonora y Coahuila, así como a las ciudades maquiladoras fronterizas, tradicionales proveedoras del sector; y para profundizar los efectos económicos cayeron las remesas que miles de mexicanos enviaban a sus familias desde Estados Unidos, donde tenían cada vez menos trabajos.

Este apretado recuento de las crisis económicas puede dar la dimensión del debilitamiento de la economía mexicana y para dar sólo un ejemplo de sus efectos vale la pena decir que durante el sexenio de Carlos Salinas de Gortari se tomó una medida de forma: una "quita de tres ceros" a la expresión de las cantidades en moneda nacional, para generar una percepción de una menor profundidad de las crisis; se trató 
sólo de una medida gráfica, en el papel, en los billetes; pero no en la realidad, de tal manera que el verdadero precio del peso mexicano frente al dólar en 2015 no es de 17.00 por dólar; sino de 17000.00 pesos por un dólar.

\section{El giro hacia la oposición y la transición}

La sociedad mexicana durante los años de la revolución sufrió la desarticulación de los órdenes económicos, políticos, sociales y culturales, propios de una guerra civil, así que en los ańos 30 se encontraba fraccionada, dolida y sin marcos organizativos. La corriente que logró cohesionarlos fue el Nacionalismo Revolucionario y pudo no sólo homogenizar a una sociedad muy diferenciada en lo cultural, lo racial, económicamente y regionalmente; también era su intención llegar a una integración política para ser la base de consensos generales y particulares para gobernar (Loaeza, 2008). Esto se fue consolidando durante el Desarrollo Estabilizador, en el que también se tuvo un crecimiento poblacional muy importante ${ }^{4}$ (Alba, 1982).

Este crecimiento poblacional, su concentración en ciudades y el modelo económico de sustitución de importaciones creó mercados importantes con cierto poder adquisitivo, y una clase media dependiente de los empleos que creaba el gobierno. Y aquí hay que detenerse un poco en el análisis: no se pensó en un Estado eficiente sino en uno que diera base política al dominio hegemónico del PRI, por eso hay una línea de conducción muy clara entre la política de masas descrita arriba y la conformación de la burocracia gubernamental de todo nivel. El trabajo de los burócratas dependía de su obediencia a los superiores jerárquicos, quienes a su vez estaban ligados al partido, y con frecuencia a una camarilla política en su interior.

4 En los 30 años posteriores a los años 40, la población de México aumentó en un 157 \% que se debió a la reducción de la mortalidad (Alba, 1982). 
Por otra parte la política de reparto agrario del cardenismo, y la fundación de Banrural y otros organismos encargados del fomento al desarrollo del agro, que en la práctica se convirtieron en instancias de control de quienes se quedaban en el campo, frenaron el desarrollo de la cultura política en amplias regiones de México. El campesinado se convirtió en un sector que siempre estaba planteando peticiones, pero también en la reserva de votos más importante en las elecciones, el "voto verde".

En las urbes los migrantes se fueron integrando a nuevas formas de organización y sus expectativas crecieron, fundamentalmente por las posibilidades de educación y de movilidad social que permitía el crecimiento del Instituto Politécnico Nacional, primero, y la masificación de la Universidad Nacional Autónoma de México en el centro del país, y la fundación en los años 70 de la Universidad Metropolitana, todas concentradas en la ciudad de México, amén del que existían ya importantes escuelas privadas como el Tecnológico de Monterrey y la Universidad Iberoamericana.

El desarrollo estabilizador propició dos décadas de crecimiento sostenido, tiempo suficiente para que sectores importantes que habían llegado del campo pudieran ver graduar a sus hijos nacidos en la ciudad y conseguir empleos en los servicios y en la planta industrial protegida.

En un proceso posterior Soledad Loeza apunta un fenómeno interesante: el debilitamiento económico del área metropolitana de la ciudad de México y el desarrollo de economías regionales, fundamentalmente en el norte, como uno de los fenómenos precursores de una clase media (pequeños empresarios) que van a nutrir la oposición en la década de los 80 (2008).

En este panorama podemos explorar cómo nació la oposición en México: el punto de arranque de la conversión del pequeño empresariado norteño a la opción de derecha (Partido Acción Nacional), es la crisis de los precios del petróleo de 1982, la devaluación que la acompañó y la nacionalización de la banca que lo confrontó con grupos económicos regionales en Monterrey, Chihuahua y Puebla entre otros. 
Por un efecto doble, del quebranto de la economía fronteriza derivado de la devaluación y por el otro la pérdida de banco como Comermex o Banorte, se tradujo en una ruptura de las clases medias con el PRI, y en las elecciones municipales de 1983 le cobraron la factura dando un triunfo inobjetable al PAN en las importantes ciudades de Chihuahua, Ciudad Juárez y Durango. Estos triunfos fueron la base para la campańa por la gubernatura del Estado de Chihuahua en 1986, cuando el gobierno priista no permitió el triunfo de Francisco Barrio y puso en marcha una serie de mecanismos ilegales para debilitarlo y aislarlo. Es importante establecer que Francisco Barrio no era panista antes de ser candidato a la alcaldía de Ciudad Juárez en 1983, sólo era uno de los empresarios afectados por la crisis.

El escenario cambia en 1991 cuando vemos emerger a nuevos actores de entre las filas de Acción Nacional, en este caso en la región central de México, particularmente en el Estado de Guanajuato, de una tradición religiosa muy acendrada. En este año son muy cuestionados los resultados electorales para la gubernatura del Estado, que había oficialmente ganado el ex regente capitalino Ramón Aguirre; quien presionado desde la presidencia fue obligado a renunciar. El gobernador interino fue Carlos Medina Plasencia y provenía del PAN. Esta sustitución fue la plataforma para el grupo de Vicente Fox, otro empresario local, quien comenzaría así su carrera hacia la presidencia en el año 2000.

La segunda oposición importante es la de centro-izquierda, y esta se generó como resultado del desarrollo de la población universitaria de la ciudad de México, del descontento de las clases medias por la pérdida de su poder adquisitivo, como resultado de la tercera crisis (1987) y de la recuperación simbólica de las banderas de la Revolución en la figura del hijo de Lázaro Cárdenas -el presidente que puso el mayor empeño en el cumplimiento de las promesas del movimiento revolucionario a favor de obreros y campesinos- Cuauhtémoc Cárdenas, quien en las elecciones de 1988 se presentó como candidato opositor a la presidencia. Cuauhtémoc Cárdenas había sido militante del PRI, pero en 1987 cuando el vuelco institucional de su partido se alejó del nacionalismo 
revolucionario, crean una "corriente democratizadora" que se opone al corrimiento hacia la derecha y al modelo neoliberal en la economía.

La gran fuerza de Cárdenas en las elecciones federales de 1988 provino del descontento de las clases medias urbanas y de los campesinos que rendían honor a la memoria de su padre. Pero también es importante destacar que un gran sector popular de la capital del país se encontraba movilizado desde 1985, cuando se dieron los terremotos de la Ciudad de México, que dańaron de manera importante la vivienda depauperada de los barrios centrales de la capital del país. La inadecuada respuesta del gobierno federal a la emergencia y la rápida organización de la Coordinadora Única de Damnificados, hizo inoperantes los controles corporativos a los que estaba habituado el partido en el gobierno (Esteve, 1992).

Otro grupo que se va a volcar a favor de la candidatura es el movimiento de mujeres que se habían nutrido de las mujeres provenientes del Movimiento Urbano Popular, y cuya incorporación, no libre de conflictos, se da a partir de 1987 cuando tiene lugar un masivo Encuentro Feminista Latinoamericano y del Caribe en la ciudad de Taxco.

La movilización de 1988 finalmente solidifica en la fundación de la tercera fuerza política de México, el Partido de la Revolución Democrática (PRD), de orientación centro izquierdista y fundado por el ex candidato Cuauhtémoc Cárdenas. Que se vuelve un instrumento valioso en sus primeros ańos, al propiciar la llegada de militantes de izquierda a gobiernos municipales, estatales, y el de la ciudad de México, además de participar fuertemente en la contienda por la presidencia en el año de 2006.

Para finalizar el siglo, y para sorpresa de una gran mayoría de mexicanos, el primero de enero de 1994, el día que se ponía en marcha el Tratado de Libre Comercio de Norteamérica, un inesperado levantamiento guerrillero anunció, para el régimen de Carlos Salinas de Gortari, la oposición de izquierda más extrema, la de las armas. Lo peculiar de esta guerrilla es que, a diferencia de otros movimientos de la región de América Latina, sólo tuvo 11 días de combate, tras lo cual se desarrolló 
en un plano político y simbólico, y dadas estas condiciones se puede afirmar que la principal arma de este movimiento fue el idioma español, magnificado por los modernos medios de comunicación, que anunciaron a todo el mundo, el fin de la estabilidad política característica del sistema político mexicano. Y lo pudo hacer porque lo sostuvo una activa sociedad civil que frenó la contraofensiva del gobierno federal, y le abrió espacio político a las demandas de los zapatistas y los otros movimientos indígenas (Flores, 2004).

\section{¿Qué es lo que movió a la sociedad a salirse de los controles autorita- rios que habían funcionado muchos años?}

Como lo explica Malloy, la naturaleza misma del populismo en América Latina es "no ser revolucionario, en el sentido de pugnar por una ruptura radical con el pasado y una reorganización total de las estructuras existentes. Por el contrario, fue un intento reformista de efectuar transformaciones estructurales limitadas tendientes a adaptarse a nuevas exigencias, manteniendo, a la vez, una continuidad básica con las tradiciones culturales del pasado" y esto se cumplió hasta que la contradicción del modelo generado por las elites se confrontó con la realidad de las crisis de fin de siglo (Camp, 1997).

Estos regímenes de la post revolución y de la postguerra pueden ser clasificados como lo hacía el propio Camp como un semi autoritarismo o como lo hace Laurence Whitehead, una democracia furtiva en la que suceden algunas cosas básicas de la democracia, pero que carecen de otros indispensables como incertidumbre en las elecciones y la percepción de los electores de que su voto sirve más allá de ratificar decisiones previas (Garrentón y Newman, 2001).

Como bien lo nota Soledad Loaeza el efecto de la movilización de estudiantes de 1968 y su matanza, no fue inmediato, y de hecho las siguientes elecciones, las de 1970, fueron tranquilas, y aún más las de 1976, en cuyas boletas electorales aparecía sólo el nombre de José López 
Portillo y así mostraron toda la fuerza del control hegemónico del PRI; sin embargo, allí donde no podía verse tan fácilmente el descontento se fue generalizando en las clases medias urbanas, en los empresarios, y en los sindicalistas independientes; y sobre todo en una generación que no conoció el México del Desarrollo Estabilizador. Estos sectores registraron en su historia vital los fuertes efectos de las crisis económicas, hasta no poder suponer que los sexenios terminaran sin que estallara una de ellas. De ellos provino el impulso por oponerse al populismo y al neoliberalismo, presionando con la actuación en el espacio público para avanzar hacia una democracia sustantiva.

La aparición de corrientes de oposición mostró al mismo tiempo el agotamiento del modelo cuya aspiración era la hegemonía, y un camino abierto hacia una mejor calidad democrática, los contrapesos entre los poderes y la alternancia en el poder. Pero una nueva crisis económica en el 2008; así como la aparición de poderes fácticos como el narcotráfico y las televisoras, abrieron un escenario insospechado en el proceso mexicano: grandes sectores sociales de derecha y de izquierda se comenzaron a separar de los partidos en los que habían confiado PAN y PRD, los cuales comenzaron a tener estrepitosas derrotas a partir de la segunda década del siglo XXI.

El regreso al poder presidencial del Partido Revolucionario Institucional, en medio de un escándalo de compra de votos y la injerencia determinante de las televisoras en dicho triunfo, así como el descrédito de la oposición de izquierda de participar en el Pacto por México; y los rescoldos de la derrota del PAN en las elecciones de 2012, han debilitado las bases sociales de la oposición y la credibilidad en el sistema de partidos.

En lo que va del sexenio del presidente Enrique Peńa Nieto, la sociedad se va separando cada vez más de los partidos, en especial el grueso de la pirámide poblacional, los menores de 30 ańos, que tienen, como sus abuelos tuvieron, una reacción de no participación en el espacio público; pero el resultado de las elecciones intermedias de 2015, que en los números favorecieron a la coalición PRI-PVEM, y que formal- 
mente fueron legales, arrojan una sombra de duda sobre la calidad de la democracia y muestran un nuevo fenómeno: la elección exitosa de los independientes. Basada, ya no en el marketing político tradicional: la compra del voto por utilitarios, despensas o materiales de construcción; sino una nueva forma de hacer política y de encausar la inconformidad de grandes sectores sociales a través de las redes sociales y de una publicidad "emocional" enfocada a los sectores populares.

En 1983 y 1988, la oposición de derecha y de centro-izquierda, usó las plazas y los pocos espacios de los medios de comunicación a su favor, y comenzó el camino de una oposición verdadera, convocando con su discurso y actuación a la sociedad en torno a los partidos, como una vía para emitir votos de castigo; el descrédito de estas fuerzas políticas como representantes de amplios sectores, perfila a nuevos actores, inspirados en estrategias de actores políticos como Podemos (2014), Ciudadanos (2015) en España. Así ganaron, con una victoria clara, como gobernador, Jaime Rodríguez Calderón, El Bronco, en el Estado fronterizo de Nuevo León, y Pedro Kumamoto, un joven de 25 ańos, ahora diputado local del central Estado de Jalisco. Y de nuevo la clave está en cómo logran dialogar, convencer y llevar a la acción a una sociedad que había optado por retirarse del espacio público.

La manera como se dieron las elecciones intermedias de 2015 muestra cómo el reto mexicano sigue siendo cómo incentivar la participación política de la sociedad.

\section{Bibliografía}

Camp, R. (1997). La democracia en América Latina: Modelos y ciclos. México: Fondo de Cultura Económica.

Castellanos, L. (2007). México armado 1943-1981, México: Editorial Era.

Córdova, A. (1974). La política de masas del cardenismo. México: Editorial Era. 
Díaz, H. (coord.) (1992). Los movimientos sociales urbanos, México: Ed. Instituto de Proposiciones Estratégicas A. C.

Garretón, M. y Edwar Newman (2001). Democracy in Latin america: (Re)constructing political society. USA: Ed. United Nations University Press.

Hobsbawm, E. (1998). Historia del Siglo XX, Buenos Aires: Ed. Crítica. Loaeza, S. (2008). Entre lo posible y lo probable. La experiencia de la transición en México. México: Ed. Planeta. Serie Temas de hoy.

Mainwaring, S. y Matthew Soberg Shugart (comp.) (2002). Presidencialismo y democracia en América Latina. Buenos Aires: Ed. Paidós.

Meyer, L. (2005). El Estado en busca del ciudadano. Un ensayo sobre el proceso político mexicano contemporáneo. México: Ed. Océano.

Rodriguez, M. (2011). Construcciones sociales y actores politicos en México y América Latina. Morelia: Universidad de San Nicolás de Hidalgo. Salinas, D. (coord.) (2006). Democratización y tensiones de gobernabilidad en América Latina. México: Ed. Gernika.

Torres, B. (1984). Historia de la revolución mexicana (1940-1952). México: Ed. Colegio de México.

Referencias electrónicas

Alba, F. y Joseph E. Potter. (1982) "Población y desarrollo en México, una síntesis de experiencia reciente". Visita del 1 de septiembre 2015. Disponible en:

http://codex.colmex.mx:8991/exlibris/aleph/a18_1/apache_ media/1RKQ5DXEHM7HT1KB3AYYGJNNMM9FXL.pdf

Velázquez, G. (2008). "La Ciudadanía en las Constituciones Mexicanas del Siglo XIX: Inclusión y Exclusión Político-Social en la Democracia Mexicana", Acta Universitaria, Vol. 18 Número especial 1, Septiembre 2008. Universidad de Guanajuato. Visita del 1 de septiembre de 2015. Disponible en:

http://www.actauniversitaria.ugto.mx/index.php/acta/article/ download/131/115 